\title{
STUDENT VALUES AND PRESTIGE STRUCTURE WITHIN TWO SECONDARY SCHOOL SYSTEMS
}

\section{MICHAEL LACY ${ }^{1}$}

University of Kansas

Mid-American Review of Sociology, 1976, Vol. 1, No. 2:7-18

\section{ABSTRACT}

Two factors are hypothesized to underlie the prestige of students within secondary school systems: family background, and personal qualities of the student. In a survey of two school systems, this hypothesis was not supported. An additional hypothesis suggested that the content of student values should An additional hypothesis suggested that the content of student values should
become more like those of the adult world as the students progress through high school; this was partially supported. The prestige values cited by student respondents are similar to those found in earlier studies by Coleman and Hollingshead. However, a new complex of anti-establishment values is also revealed in student responses.

\section{BACKGROUND}

This report analyses a study of the "status elite" in two secondary school systems. The objective of the study was to investigate various factors underlying the status of the elite, and to attempt to assess what changes may occur in these underlying factors as the students progress from the eighth to the twelfth grades.

To begin, a definition of "status elite" is in order. By "status elite" we refer to the distribution of prestige within the system. Member of the status elite, then, are those students who are accorded the highest level of prestige by the other students. The status of a student is not an individual phenomenon; rather it is a collective fact. Thus, the students in the status elite are not simply those whom the largest number of other students like. Instead, the status elite is a group of students recognized as having high prestige by the consensus of other students.

Coleman, in his study, Adolescent Society, used four different questions to determine the composition of the status elite, which he referred to as the "leading crowd" (Coleman, 1961:102). Each of Coleman's four questions pointed at a different aspect of being a leader. The students were asked to name other students who (a) they were actually friends with; (b) they would like to be friends with; (c) they would like to be similar to; and (d) are in the the leading crowd (Coleman, 1961:98). 
This last question elicited choices with by far the highest degree of consensus. ${ }^{1}$

Hollingshead used a reputational technique to determine the leading crowd in his study (Hollingshead, 1949:220). His technique suggests the idea that there exists a consensus about membership in the leading crowd. Also, Hollingshead treated the leading crowd as a group based on reputation, which in his usage is essentially synonymous with prestige (Hollingshead, 1949:220).

Gordon used three factors for rating the "general social status" of the student (Gordon, 1957:3). One of these factors, the student's rank in the informal system, corresponds roughly to the same dimension of prestige as our notion of status elite. Gordon ranked the students on the basis of a "best friends" choice sociometric test. However, this is not an adequate method for determining the leading crowd. The fact that an individual is chosen most frequently as a best friend does not mean he has high prestige. In fact, students frequently express dislike of peers whom they acknowledge to be members of the leading crowd. Thus, for our purposes, Gordon's method for determining the status elite may be rejected. While Hollingshead's reputational technique is perhaps the most desirable for determining the leading crowd, it was judged to be impractical for use in this study. Consequently, Coleman's question, \#7 in our questionnaire, was used as an approximation of the reputational technique.

After having theoretically and operationally defined the leading crowd, we had to determine the bases of membership in the leading crowd. In general, one can conceive of the prestige of the leading crowd as being based on their possession of objects and qualities which are valued by the students as a whole. Hollingshead notes that the students value "careful grooming, proper language, and such character traits as honesty" (Hollingshead, 1949:20). In addition, he characterizes the status elite as being leaders "in extracurricular activities, . . , in church work, in the youth groups, and in social affairs" (Hollingshead, 1949:22).

Gordon suggests that the "prestige values" of the school he studied were as follows: "grade achievement, grade rank, organized activities, clique membership, dating, dress, manners and morals, and socio-economic position based on the occupation of the father" (Gordon, 1957:99). Coleman's respondents mentioned similar valued items as being necessary

1 This study was partially supported by a National Science Foundation Undergraduate Research Participation Award at the University of Kansas in 1971-1972. The author would like to acknowledge the assistance of Robert Palmer on this project. for being in the leading crowd. These included such things as personality, athletics, having car, good grades, good looks, and good clothes (Coleman, 1961:40). Of these, athletics appears to be the "clearest path to membership in the leading crowd" (Coleman, 1961:41). Thus, generally, the same qualities seem to be the prestige values in all of these studies.

However, there is considerable theoretical disagreement over the importance of the status in the community of a student's family. Hollingshead considered family status to be extremely important, in that he found it to be the primary basis by which students judged one another. $\mathrm{He}$ claimed that the "rating a child receives from his fellows is a function on the whole of his family's position in the community's prestige structure rather than of any position in the peer group which the student creates himself" (Hollingshead, 1949:223). Coleman, on the other hand, found that family background characteristics were important in only half of the schools he studied. In Elmtown, the city on which Hollingshead's study is based, Coleman did not find family background to be important (Coleman, 1961:94-96). Gordon found that family status was a salient value and that "a significant number of prestige values are derived from income and family position" (Gordon, 1957:100). This range of ideas about the importance of family status for membership in the leading crowd suggests that this is an important area for further research.

Another area of some question is that of changes in the informal social system that occur during the time students progress through high school. Gordon noted an increasing competition for prestige as the students moved to their senior year, and a "year by year acceleration in . . participation" in school activities (Gordon, 1957:32). Hollingshead found that the frequency of association between students of differing family status decreased from the ninth to the twelfth grade (Hollingshead, 1949:211-212). Coleman discovered an overall decrease from the freshman year to the senior year in the importance of good grades as a route into the leading crowd (Coleman, 1961:169). There is a general disregard of the possibility of changes in the status and value system as the students progress through school. Thus, this area also merits further research.

With these two problems in mind, namely the importance of family status and the issues of changes over time in the status and value system, we developed a general hypothesis. To begin, one must note two analytically separable factors underlying the status of an adolescent in his school. 
These are (1) the value system of his peers vis-a-vis the youth's own qualities, and (2) the status of his family in the larger community. The hypothesis is as follows: for individuals in the eighth grade, family status will be the less important factor. However, as students progress to the twelfth grade, their status will be increasingly dependent on their family's status. This should occur for two reasons: (1) because the older students come to hold values more like those of their parents; and (2) because items and activities requiring money, such as dating, possessing a car, having expensive clothes, come to be more important as the student gets older. As a specific case of this hypothesis, the leading crowd should become increasingly composed of students with high family statuses as it moves from the eighth through the twelfth grade. Testing this specific case was the main objective of this study. Also, changes in the value system were assessed, as well as differences in the prestige values held by different groups of students.

\section{PROCEDURE}

The study was conducted in two different Kansas communities, these communities will be referred to as "Uniontown" and "Oaktown," in order to preserve their anonymity. These communities were chosen because they both have secondary school systems organized on a 3-3 basis, i.e., the junior high has grades 7-9 and the senior high has grades 10-12.

Uniontown's junior high has 429 pupils, and its high school 307 . The community has a population of approximately 1500, a large section of which is dependent upon one industry. The town itself is not the only source of students; since the schools are part of a unified system, they also draw from rural areas and a suburban area. Oaktown's junior high has 664 students; its high school has 604 . This community of 11,000 centers around a small college; however, the schools also contain students from farm families and a considerable number whose fathers commute to industrial jobs in larger cities.

In Oaktown, the questionnaire (see Appendix I) was administered to a sample of students in grades eight through twelve. The samples were selected to represent a cross section of students in each grade. From the preliminary questionnaire, the leading crowd for each grade was determined. The leaders were then mailed a copy of the same questionnaire which they later returned.

The procedure in Uniontown was similar. The questionnaire was administered to half of the students in both the eighth and ninth grades. In the high school, the qunestionnaire was administered to samples as in

Oaktown. The procedure followed for the leading crowds was identical to that in Oaktown.

In each community, a socio-economic status (SES) distribution was obtained. The education and occupation of the head of the household was obtained from questions 3-6 on the questionnaire. The responses were categorized as follows for education: (1) completed college; (2) completed some college; (3) completed high school; (4) completed some high school; (5) completed eight years or less. Occupation was categorized with a modified version of the United States census system: (1) professional, technical or kindred occupation; (2) manager, official, or proprietor, including farmers who own their own farms; (3) clerical and sales personnel; (4) craftsmen and foremen; (5) unskilled workers (Bonjean, et al., 1967:424). These two indicators of socio-economic status were summed for each respondent's father or head of household. The sums were then divided into five categories, resulting in the distributions in tables I and II in appendix II.

The leading crowds for each grade were obtained from question \#7 on the questionnaire. The number of times a given student was mentioned was totaled. The leading crowd members were those students mentioned whose scores ranked them above a clear breaking point. The following example of the ninth grade at Uniontown will clarify the procedure:

number of times a student was mentioned

\begin{tabular}{r|rl} 
& \multicolumn{2}{|c}{$\begin{array}{c}\text { number of students with this } \\
\text { frequency of being mentioned }\end{array}$} \\
17 & 1 & - \\
15 & 1 & seven members of the \\
14 & 1 & leading crowd \\
12 & 2 & \\
9 & 2 & breaking point \\
7 & 5 & \\
5 & 4 & \\
4 & 1 & \\
3 & 12 & \\
2 & 7 & \\
1 & 24 &
\end{tabular}

Utilizing information from the questionnaires, we placed the leading crowd members in each grade into a socio-economic status category. They were categorized on the basis of their father's occupation and education. This distribution appears in tables III and IV in appendix II.

The other important segment of data was that of prestige values. This information was obtained from question \#8 on the questionnaire. Due 
to the nature of the question, the information is perhaps most accurately described as "attributes perceived as important for membership in the leading crowd." The responses to this question should reflect the actual prestige values. On this question, the responses were categorized into five value complexes. These are (A) "Anti-Establishment" values such as drinking, drug use, arrogance, and other generally counter-cultural attitudes and attributes; (B) "Traditional Personal Characteristics" including good looks, personality, sense of humor, being a Christian, not using drugs, not being arrogant, etc.; (C) "Personal Pecuniary Characteristics" such as clothing, having money, having use of a car, and having parents with high socio-economic status; (D) "School Related" values including grades and extracurricular activities; and (E) Athletics. All codable responses to question \#8 were placed in the appropriate category. The total number of responses in each category was then tabulated, and the percentage of all codable responses which fell in each category was calculated. Some responses were not codable because they were bizzare, mentioned infrequently, and thus did not fit into any of the five categories. These uncodable responses comprised $18 \%$ of the responses at Oaktown and 28\% at Uniontown. This method was used in tabulating the responses at each school by sex, socio-economic status, grade in school, and for the leading crowd (see tables V-XII).

\section{RESULTS}

The major hypothesis to be tested was that the leading crowds will be increasingly recruited from the upper socio-economic status groups, as one progresses from the eighth to the twelfth grade. Tables II and IV show that the opposite case, if anything, was true in Uniontown. For Oaktown, tables I and III indicate that there do not appear to be any significant changes in the socio-economic status composition of the various leading crowds. However, in both cases the average socio-economic status of the leaders was-over 0.5 higher than the average of the other students as a whole.

Another hypothesis was that as the students go from eighth through twelfth grade, they should be developing values that are more "adult." Consequently, these changes ought to be reflected in the perceived prestige values. Tables $\mathrm{V}$ and VI do indicate some changes. In both communities, "Anti-Establishment" prestige values increase in frequency from the eighth to the twelfth grade. Also, a decrease occurred in the frequency of "Traditional Personal Characteristics" being mentioned. In Uniontown, table VI shows a steady increase in "Pecuniary Character- istics"; this occurs to some extent in Oaktown (table V), but the progression is not steady because of peaks in the eighth and tenth grades. School related values do not seem to show any trend in either school. Similarly, there do not seem to be any trends in the importance of athletics. In general, tables V and VI show traditional personal characteristics to be the most important values. In Oaktown, pecuniary characteristics are second in frequency; however in Uniontown athletics is second. "AntiEstablishment" values rank third in both communities.

Socio-economic status background also is related to the values cited by a student. One might expect the lowest groups to cite pecuniary characteristics more frequently, since these students are more likely to be adversely affected in their claims for prestige at school by the necessity of these characteristics. However, this is the case only in Oaktown where the lowest status group mentioned pecuniary characteristics two and one-half times as frequently as did the highest SES group in Oaktown. In Uniontown, anti-establishment values increase in frequency in the lower socio-economic groups; the opposite appears to occur in Oaktown.

As one might expect, there are considerable differences in the attitudes mentioned by girls as opposed to boys. In both Oaktown and Uniontown, athletics were mentioned much more frequently by the boys. Also, in both cases, girls cited traditional personal characteristics more frequently.

One might also expect to observe differences in the prestige values cited by the leading crowd members. Considering that the leading crowd is likely to be a particularly salient force in determining these values, the leading crowd may be considered in a sense to be the ideology makers in a junior high school or high school. One would expect that their values would not be ones likely to place them in an unfavorable light. In particular, one would expect them to mention pecuniary characteristics less frequently. It seems unlikely that they would admit that these "undemocratic" values are necessary. Table XII as compared to table VI, and table XI as compared to table V support this hypothesis. In both communities, the leading crowds as a whole mentioned pecuniary characteristics (C) considerably less frequently than did the other students as a whole. Traditional personal characteristics were cited somewhat more frequently by the leading crowd. This also supports the general hypothesis that the leading crowd will mention values that will reflect favorably on them. Denigrating ascriptive criteria while upholding achieved criteria is one way of doing this. 


\section{CONCLUSIONS}

Our findings in this study tend to support previous research in this area. Essentially, the same prestige values were observed as were observed in previous studies. The importance of athletics as a prestige value, as Coleman and Hollingshead found, must not be overlooked. In this study, athletics was the only value complex which corresponded to one particular codable response. There were a number of types of responses categorized in each of the other four categories. In view of this, the frequency with which athletics was cited becomes more striking.

The major hypothesis, namely that socio-economic status of a student's family increases in importance as he goes through school, was not supported. This seems somewhat paradoxical, in view of the increasing importance of pecuniary characteristics and the decreasing importance of traditional personal characteristics as the student progresses through school. These two value changes seem to indicate a move toward the prestige values of adult society. If socio-economic status is really a valid indication of prestige among adults in the United States, one would expect an increase in the importance of socio-economic status as a prestige value in secondary schools.

There exists a good theoretical explanation for this paradox. One must take note of the increasing importance of anti-establishment values as one goes through the school system. One may assume that this increase is accompanied by a progression toward other counter cultural values, such as egalitarian notions. These notions might decrease the prestige value of family background. A move toward these counter cultural values would also have the observed effect of decreasing the prestige value of traditional personal traits. Pecuniary prestige values would still increase in importance, since elements of the counter culture such as the use of marijuana require considerable financial means. Thus, the increase in anti-establishment values, along with egalitarian notions, might have decreased the average socio-economic status of the leading crowd. This increase should balance or override the increase in importance of pecuniary values, thus eliminating a possible accompanying trend towards increased importance of socio-economic status.

The increased importance of anti-establishment values might be considered a temporary historical distortion of the prestige system in the leading crowd. However, this merely points out the necessity of placing social research findings such as this within a particular historical context.

\section{APPENDIX I}

\section{Student Values and Status Questionnaire}

1. What is your sex? ..... Male _... Female

2. What grade are you in at school? (circle one) $891011 \quad 12$

3. Indicate, by circling a number, the highest grade in school completed by your father and mother. (If you live with a step-parent or guardian, give his or her education.)

\begin{tabular}{lclllll} 
& Elementary & \multicolumn{1}{c}{ High } & & Graduate or & \\
& School & School & College & Professional & Degrees \\
Father & 8 or less & 9101112 & 1234 & 12345 & \\
Mother & 8 or less & 9101112 & 1234 & 12345 & -
\end{tabular}

4. What is your father's (step-father's or guardian's) job or occupation? (If he is not living, indicate what his occupation was.)

5. Describe what your father does in this occupation.

6. Does your father work for some business or organization, or does he own his own business or farm?

7. Suppose someone new moves to your school and wants to get in with the leading crowd. What students in your grade should he or she get to know? (Please give first and last names.)

8. What does it take to make it big with the other students here? What kind of things does a student need to be or to have in order to be a member of the leading crowd of your grade? 


\section{APPENDIX II}

\section{OAKTOWN}

TABLE I: Socio-economic status distribution:

\begin{tabular}{cccccc}
\multicolumn{2}{l}{ High } & \multicolumn{4}{c}{ Low } \\
& 2 & 3 & 4 & 5 & Total \\
\hline \hline 2 & 3,4 & 5,6 & 7 & $\begin{array}{c}8,9 \\
10\end{array}$
\end{tabular} indicators

Percentage of respondents in category

$\begin{array}{llllll}13 \% & 16 \% & 30 \% & 22 \% & 19 \% & 100 \%\end{array}$ $\begin{array}{llllll}30 & 37 & 67 & 49 & 40 & 223\end{array}$

Mean Status is 3.17

TABLE III: Socio-economic status of leading crowd in each grade:
Categories

\begin{tabular}{ccccccc} 
& \multicolumn{7}{c}{ Categories } \\
& High & \multicolumn{4}{c}{ Low } \\
& 1 & 2 & 3 & 4 & 5 & Total \\
\hline \hline 8 & $18 \%$ & $36 \%$ & $46 \%$ & $0 \%$ & $0 \%$ & \\
& 2 & 4 & 5 & 0 & 0 & 11 \\
\hline 9 & $38 \%$ & $0 \%$ & $50 \%$ & $12 \%$ & $0 \%$ & \\
& 3 & 0 & 4 & 1 & 0 & 8
\end{tabular}

Grade

\begin{tabular}{cccclll}
10 & $14 \%$ & $43 \%$ & $43 \%$ & $0 \%$ & $0 \%$ & \\
& 1 & 3 & 3 & 0 & 0 & 7 \\
\hline 11 & $25 \%$ & $50 \%$ & $25 \%$ & $0 \%$ & $0 \%$ & \\
& 1 & 2 & 1 & 0 & 0 & 5 \\
\hline 12 & $20 \%$ & $40 \%$ & $40 \%$ & $0 \%$ & $0 \%$ & \\
& 1 & 2 & 2 & 0 & 0 & 5 \\
\hline Total & $23 \%$ & $32 \%$ & $43 \%$ & $2 \%$ & $0 \%$ & \\
& 8 & 11 & 15 & 1 & 0 & 35
\end{tabular}

\section{UNIONTOWN}

TABLE II: Socio-economic status distribution: Categories

High
\begin{tabular}{cccccc}
1 & 2 & 3 & 4 & 5 & Total \\
\hline \hline 1,2 & 4,5 & 6,7 & 8 & 9,10 & \\
3 & & & & & \\
\hline $9 \%$ & $13 \%$ & $51 \%$ & $12 \%$ & $15 \%$ & $100 \%$ \\
24 & 37 & 143 & 35 & 42 & 281
\end{tabular}

Mean Status is 3.47

TABLE IV: Socio-economic status distribution of leading crowd in each grade: Categories

\begin{tabular}{cccccc}
\multicolumn{2}{l}{ High } & \multicolumn{4}{c}{ Low } \\
1 & 2 & 3 & 4 & 5 & Total \\
\hline \hline $13 \%$ & $13 \%$ & $63 \%$ & $0 \%$ & $13 \%$ & \\
1 & 1 & 5 & 0 & 1 & 8 \\
\hline $17 \%$ & $33 \%$ & $17 \%$ & $17 \%$ & $17 \%$ & \\
1 & 2 & 1 & 1 & 1 & 6 \\
\hline $22 \%$ & $22 \%$ & $56 \%$ & $0 \%$ & $0 \%$ & \\
2 & 2 & 5 & 0 & 0 & 9 \\
\hline $14 \%$ & $14 \%$ & $72 \%$ & $0 \%$ & $0 \%$ & \\
1 & 1 & 5 & 0 & 0 & 7 \\
\hline $0 \%$ & $20 \%$ & $40 \%$ & $40 \%$ & $0 \%$ & \\
0 & 1 & 2 & 2 & 0 & 5 \\
\hline $14 \%$ & $20 \%$ & $51 \%$ & $9 \%$ & $6 \%$ & \\
5 & 7 & 18 & 3 & 2 & 35
\end{tabular}

\section{OAKTOWN}

TABLE V: Prestige values cited by grade:

Categories

\begin{tabular}{ccccccc} 
& A & B & C & D & E & Total \\
\hline \hline 8 & $4 \%$ & $60 \%$ & $17 \%$ & $12 \%$ & $7 \%$
\end{tabular}

\begin{tabular}{cccccc}
4 & 55 & 16 & 11 & 6 & 92 \\
\hline
\end{tabular}

$\begin{array}{lllllll}\text { Grade } & 10 & 19 \% & 36 \% & 28 \% & 7 \% & 10 \%\end{array}$

\begin{tabular}{clllcll} 
& 15 & 28 & 22 & 5 & 8 & 78 \\
\hline 11 & $13 \%$ & $47 \%$ & $21 \%$ & $12 \%$ & $7 \%$ &
\end{tabular}

$\begin{array}{lllllll} & 11 & 40 & 18 & 11 & 6 & 86\end{array}$

\begin{tabular}{clllcll}
12 & $22 \%$ & $38 \%$ & $21 \%$ & $12 \%$ & $7 \%$ & \\
18 & 31 & 17 & 9 & 6 & 81 \\
\hline
\end{tabular}

\begin{tabular}{llllll}
\hline Total & $14 \%$ & $49 \%$ & $20 \%$ & $10 \%$ & $7 \%$
\end{tabular} $\begin{array}{llllll}58 & 204 & 83 & 41 & 29 & 415\end{array}$

\section{OAKTOWN}

TABLE VII: Prestige values cited by socio-economic status:

Value Category

\begin{tabular}{ccccccc} 
& A & B & C & D & E & Total \\
\hline \hline 1 & $15 \%$ & $56 \%$ & $13 \%$ & $10 \%$ & $6 \%$
\end{tabular}

\begin{tabular}{ccccccc}
1 & $15 \%$ & $56 \%$ & $13 \%$ & $10 \%$ & $6 \%$ & \\
& 8 & 29 & 7 & 5 & 3 & 52 \\
\hline 2 & $19 \%$ & $59 \%$ & $13 \%$ & $4 \%$ & $5 \%$ &
\end{tabular}

\begin{tabular}{ccccccc}
2 & $19 \%$ & $59 \%$ & $13 \%$ & $4 \%$ & $5 \%$ & \\
& 7 & 22 & 5 & 1 & 2 & 37 \\
\hline
\end{tabular}

\begin{tabular}{llllll}
\hline 3 & $11 \%$ & $48 \%$ & $18 \%$ & $14 \%$ & $9 \%$
\end{tabular}

Status

category

\begin{tabular}{lllllll} 
& 10 & 59 & 22 & 16 & 11 & 122 \\
\hline 4 & $11 \%$ & $53 \%$ & $19 \%$ & $11 \%$ & $6 \%$ & \\
& 10 & 50 & 18 & 10 & 6 & 94 \\
\hline 5 & $12 \%$ & $38 \%$ & $33 \%$ & $10 \%$ & $7 \%$ & \\
& 11 & 34 & 29 & 9 & 6 & 89 \\
\hline$a l$ & $14 \%$ & $49 \%$ & $21 \%$ & $10 \%$ & $6 \%$ & \\
& 50 & 194 & 81 & 41 & 28 & 394
\end{tabular}

UNIONTOWN

TABLE VI: Prestige values cited by grade:

\begin{tabular}{cccccc}
\multicolumn{6}{c}{ Categories } \\
\hline B & C & D & E & Total \\
\hline $8 \%$ & $71 \%$ & $4 \%$ & $5 \%$ & $12 \%$ & \\
7 & 65 & 4 & 5 & 11 & 92 \\
\hline $7 \%$ & $64 \%$ & $4 \%$ & $3 \%$ & $22 \%$ & \\
6 & 52 & 3 & 2 & 18 & 81 \\
\hline $10 \%$ & $73 \%$ & $10 \%$ & $0 \%$ & $8 \%$ & \\
6 & 45 & 6 & 0 & 5 & 62 \\
\hline $12 \%$ & $56 \%$ & $12 \%$ & $4 \%$ & $16 \%$ & \\
7 & 31 & 7 & 2 & 9 & 56 \\
\hline $18 \%$ & $47 \%$ & $15 \%$ & $8 \%$ & $12 \%$ & \\
13 & 34 & 11 & 5 & 9 & 72 \\
\hline $11 \%$ & $63 \%$ & $9 \%$ & $4 \%$ & $14 \%$ & \\
39 & 227 & 31 & 14 & 52 & 363
\end{tabular}

\section{UNIONTOWN}

TABLE VIII: Prestige values cited by socio-economic status:

\begin{tabular}{clllll}
\multicolumn{7}{c}{ Value Category } \\
A & B & C & D & E & Total \\
\hline \hline $3 \%$ & $65 \%$ & $13 \%$ & $0 \%$ & $19 \%$ & \\
1 & 21 & 4 & 0 & 6 & 32 \\
\hline $9 \%$ & $62 \%$ & $9 \%$ & $2 \%$ & $19 \%$ & \\
5 & 36 & 5 & 1 & 11 & 58 \\
\hline $12 \%$ & $61 \%$ & $12 \%$ & $4 \%$ & $11 \%$ & \\
18 & 96 & 18 & 6 & 18 & 156 \\
\hline $13 \%$ & $62 \%$ & $13 \%$ & $4 \%$ & $9 \%$ & \\
6 & 29 & 6 & 2 & 4 & 47 \\
\hline $21 \%$ & $54 \%$ & $2 \%$ & $4 \%$ & $19 \%$ & \\
10 & 26 & 1 & 2 & 9 & 48 \\
\hline $12 \%$ & $61 \%$ & $10 \%$ & $3 \%$ & $14 \%$ & \\
40 & 208 & 34 & 11 & 9 & 341
\end{tabular}


Mid-American Review of Sociology

\begin{tabular}{cllllllll} 
& \multicolumn{8}{c}{ OAKTown } \\
& Table IX: Prestige values cited \\
by sex: \\
Sex \\
& \multicolumn{7}{c}{ Value Category } \\
& A & B & C & D & E & Total \\
\hline \hline Boys & $18 \%$ & $45 \%$ & $16 \%$ & $8 \%$ & $13 \%$ & \\
& 28 & 71 & 26 & 15 & 20 & 160 \\
\hline Girls & $12 \%$ & $52 \%$ & $22 \%$ & $10 \%$ & $4 \%$ & \\
& 30 & 133 & 57 & 26 & 9 & 255 \\
\hline Total & $14 \%$ & $49 \%$ & $20 \%$ & $10 \%$ & $7 \%$ & \\
& 58 & 204 & 83 & 41 & 29 & 415
\end{tabular}

\begin{tabular}{|ccccccc}
\multicolumn{8}{c}{ UnIONTOWN } \\
TABLE X: Prestige values cited \\
by sex: \\
Value Category \\
A & B & C & D & E & Total \\
\hline \hline $11 \%$ & $45 \%$ & $8 \%$ & $4 \%$ & $32 \%$ & \\
14 & 55 & 10 & 5 & 39 & 123 \\
\hline $10 \%$ & $72 \%$ & $9 \%$ & $4 \%$ & $5 \%$ & \\
25 & 172 & 21 & 9 & 13 & 240 \\
\hline $11 \%$ & $62 \%$ & $9 \%$ & $4 \%$ & $14 \%$ & \\
39 & 227 & 31 & 14 & 52 & 363
\end{tabular}

\section{OAKTOWN}

TABLE XI: Prestige values cited by the leading crowd members in each grade: Value Category

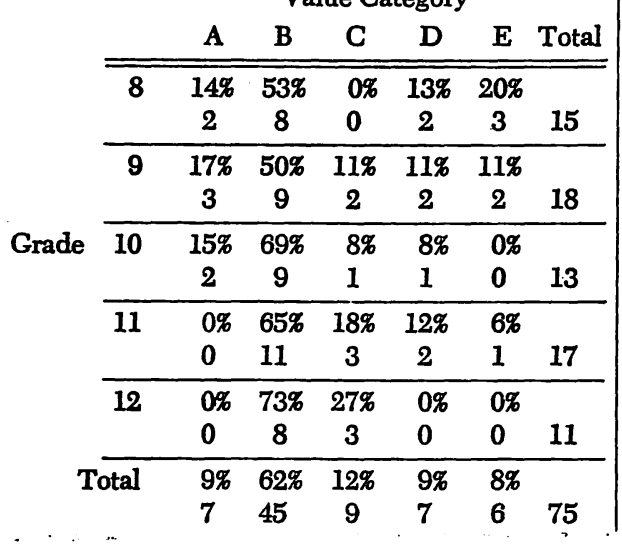

\begin{tabular}{|c|c|c|c|c|c|}
\hline \multicolumn{6}{|c|}{ 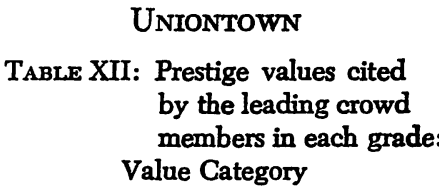 } \\
\hline $\mathbf{A}$ & B & C & D & $\mathbf{E}$ & Total \\
\hline $\begin{array}{l}0 \% \\
0\end{array}$ & $\begin{array}{c}67 \% \\
6\end{array}$ & $\begin{array}{l}0 \% \\
0\end{array}$ & $\begin{array}{c}11 \% \\
1\end{array}$ & $\begin{array}{c}22 \% \\
2\end{array}$ & 9 \\
\hline $\begin{array}{l}0 \% \\
0\end{array}$ & $\begin{array}{c}55 \% \\
5\end{array}$ & $\begin{array}{c}11 \% \\
1\end{array}$ & $\begin{array}{c}11 \% \\
1\end{array}$ & $\begin{array}{c}22 \% \\
2\end{array}$ & 9 \\
\hline $\begin{array}{c}10 \% \\
2\end{array}$ & $\begin{array}{l}57 \% \\
12\end{array}$ & $\begin{array}{l}5 \% \\
1\end{array}$ & $\begin{array}{l}4 \% \\
1\end{array}$ & $\begin{array}{c}25 \% \\
5\end{array}$ & 21 \\
\hline $\begin{array}{c}17 \% \\
1\end{array}$ & $\begin{array}{c}83 \% \\
5\end{array}$ & $\begin{array}{l}0 \% \\
0\end{array}$ & $\begin{array}{l}0 \% \\
0\end{array}$ & $\begin{array}{l}0 \% \\
0\end{array}$ & 6 \\
\hline $\begin{array}{l}0 \% \\
0\end{array}$ & $\begin{array}{c}100 \% \\
3\end{array}$ & $\begin{array}{l}0 \% \\
0\end{array}$ & $\begin{array}{l}0 \% \\
0\end{array}$ & $\begin{array}{l}0 \% \\
0\end{array}$ & 3 \\
\hline 3 & 31 & 2 & 3 & 9 & 48 \\
\hline
\end{tabular}

- The percentages in all tables were rounded off to the nearest point.

Thus, the sums may exceed $100 \%$ in some cases.

\section{BIBLIOGRAPHY}

Bonjean, Charles M., Richard J. Hill and S. Dale McLemore

1967 Sociological Measurement (Chandler, San Francisco).

Coleman, James $\mathrm{S}$.

1961 The Adolescent Society (Free Press of Glencoe, New York).

Gordon, C. Wayne

1957 The Social System of the High School (Free Press, Glencoe, Ill.).

Hollingshead, A. B.

1949 Elmtown's Youth (J. Wiley, New York).

\section{CONSENSUS, CONFLICT, AND INTERNATIONAL STRATIFICATION THEORIES OF MODERNIZATION: AN EVALUATION}

\author{
WILLIAM C. LANE \\ Kansas State University
}

Mid-American Review of Sociology, 1976, Vol. 1, No. 2:19-32

\section{ABSTRACT}

This paper reviews two of the major sociological theories of modernization, the consensus and conflict perspectives. These two theories are used to analyze some aspects of the economic and political situation in Chile. The international stratification approach is then presented as a third theory. Based upon criterio developed during the critique of the consensus and conflict theories, it is argued that the international stratification paradigm offers a synthesis of these two approaches which may be able to fulfill the requirements for a comprehensive sociological theory of modernization.

From the classical period to the present sociologists have been concerned with social change and development. Comte, Spencer and others, under the influence of Darwin, were particularly concerned with social progress. Social progress has been defined as "attempts to trace the evolution of specific social forms or entire societies from some earlier, less advanced state to a terminal, advanced state ..." (Apelbaum, 1970:18). While sociologists no longer discuss social progress, they are concerned with development and, the more inclusive process, modernization. This interest in modernization became an urgent area of study at the end of the Second World War as a result of the changing international situation, particularly in relationship to the colonial countries (Bernstein, 1971).

This paper examines two general approaches to the sociology of modernization, the consensus and conflict theories. The work of Smelser and Marx will be examined as important and representative examples of each of the respective theories. Data on social change in Chile is then used to examine the explanatory abilities of each theory. The international stratification approach, an alternative model to the conflict and consensus models, will be discussed. Based upon the evaluation of each of these approaches, some requirements for a sociological theory of modernization will be presented. 